\title{
Comparative Availability of Selected Essential Medicines for Selected Chronic Diseases in Bhiwani District, Haryana, India
}

\author{
Shashikant Jangra, Neeraj Gilhotra* \\ Department of Pharmaceutical Sciences, Maharshi Dayanand University, Rohtak - 124 001, Haryana, India.
}

\begin{tabular}{l} 
ARTICLE INFO \\
\hline Article history: \\
Received on: 08/07/2015 \\
Revised on: 01/08/2015 \\
Accepted on: $21 / 08 / 2015$ \\
Available online: $27 / 09 / 2015$ \\
\hline Key words: \\
Accessibility, Availability, \\
Chronic diseases, Essential \\
medicines, Retail pharmacy \\
outlets
\end{tabular}

\begin{abstract}
Medicines represent a substantial proportion of the economic costs for treating chronic diseases. In low and middle income countries (LMIC), 50-90\% of the population have to pay for medicines themselves. Inappropriate access and availability of essential medicines contribute substantially to out-of-budget expense. A significant population of developing countries (upto 90\%) purchase medicines through out-of-pocket payments. This research study was conducted to investigate the comparative availability of selected essential medicines for selected chronic diseases in Bhiwani district. Standardized methodology of World Health Organization and Health Action International was employed. The research study was conducted on retail pharmacy outlets of Bhiwani District i.e. residential areas of Bhiwani city and five administrative areas of Bhiwani district. Overall percent availability of the most of the surveyed medicines used in the treatment of chronic diseases was found to be less than 50\%. Dissemination of well documented information on availability medicine consumers in all residential areas may enhance consumer demand for lower price medicine and thus may serve to enhance the availability of demanded medicine (lowest priced) in all the areas of Bhiwani district.
\end{abstract}

\section{INTRODUCTION}

Medicines represent a substantial proportion of the economic costs for treating chronic diseases in most of the countries. In Latin America and the Caribbean, medicine costs account upto $44 \%$ of the direct medical costs for diabetes (Barcelo et al., 2003). Further, in low and middle-income countries $50-90 \%$ of the population have to pay for medicines themselves (Quick et al., 2002). A significant proportion of chronic disease morbidity and mortality can be prevented if medications are made accessible and affordable (WHO, 2008). Several studies have examined the availability of essential medicines; however none have focused specifically on medicines used to treat chronic diseases (Ewen, 2003). Globally, approximately 35 million deaths (60\% of all deaths) are attributable to chronic diseases each year, with more than 30 million deaths (52\% of all deaths) due to cardiovascular disease (accounting for $30 \%$ of all deaths), cancer (13\% of all deaths), chronic respiratory disease ( $7 \%$ of all deaths) and diabetes $(2 \%$ of all deaths) (WHO, 2005). World Health Organization (WHO)

\footnotetext{
* Corresponding Author

Neeraj Gilhotra, Department of Pharmaceutical Sciences, Maharshi

Dayanand University, Rohtak - 124 001, Haryana, India

Emal: neerajmdu@rediffmail.com
}

estimated that upto $30 \%$ of the world's population lack regular access to essential medicines and upto $50 \%$ in the poorest countries of Africa and Asia (WHO, 2011). Generic medicines are upto 2090\% cheaper than their innovator brands (Shafie and Hassali, 2008) and "gold standard" and "first line therapy" for many acute and chronic diseases (Sheppard, 2011), promoting generic medicines to improve medicine access both for government and individuals who have to pay out of pocket for medicines (Cameron et al., 2009). A generic medicine is identical to its corresponding innovator medicines in terms of safety, quality, efficacy, dosage form, strength and route of administration and has the same intended use as the innovator medicine (FDA, 2009). Promotion of generic medicines recommended being a part of the national medicine policy (Cameron et al., 2011) to achieve a comprehensive and sustainable health care system in Europe (Godman et al., 2010). The present study is perhaps the only study that compares the availability of generic as well as branded medicines of selected essential medicines for selected chronic diseases in a single district of any state. This research study covers whole of Bhiwani district along with administrative areas serve to document comparative availability of generic as well as branded medicines of selected essential medicines used in the treatment of chronic diseases (Hypertension, Ulcers, Diabetes, Depression) in different geographical areas of Bhiwani district. 
The method used in the present study is based on World Health Organization (WHO), Geneva, Switzerland and Health Action International Global (HAI), Amsterdam Netherland Guidelines. A manual of WHO/HAI survey methodology was released in 2003 (WHO and HAI, 2003). Later this WHO/HAI manual was updated in 2008 (WHO and HAI, 2008) to reflect the wealth of practical experience in conducting medicine price and availability survey.

\section{MATERIALS AND METHODS}

\section{Background}

Bhiwani, 21th district of Haryana is located in Northern. Other major administrative areas in district are Charkhi Dadri, Siwani, Loharu, Tosham and Bawanikhera. To investigate the comparative availability of selected essential medicines for selected chronic diseases at retail pharmacy outlets in Bhiwani city and its administrative areas were included in this study.

\section{Sampling}

This baseline data collection research study was documented at retail pharmacy outlets in different geographical and administrative areas of Bhiwani district.

\section{Medicines Surveyed}

Twenty essential medicines for selected chronic diseases in different dosage forms as shown in (table 1) were selected. To carry out survey, medicines used for the treatment of four chronic diseases (Ulcer, Depression, Hypertension, Diabetes) were selected from the National List of Essential Medicines, India 2011 (NEML, 2011) and hospital formulary of Bhiwani.

\section{Data Collection}

This survey had been designed to provide a comprehensive picture of comparative availability of selected essential medicines for selected chronic diseases in a single district of any state.

To carry out the survey WHO/HAI methodology was adopted. It is usually not feasible to Collect data from a large number of health facilities, pharmacies and other medicine outlets, so a small sample of facilities was selected in at least six geographical areas: a country's main urban centre and five other administrative areas (WHO and HAI, 2008) (survey areas) as shown in figure 1 and 2.

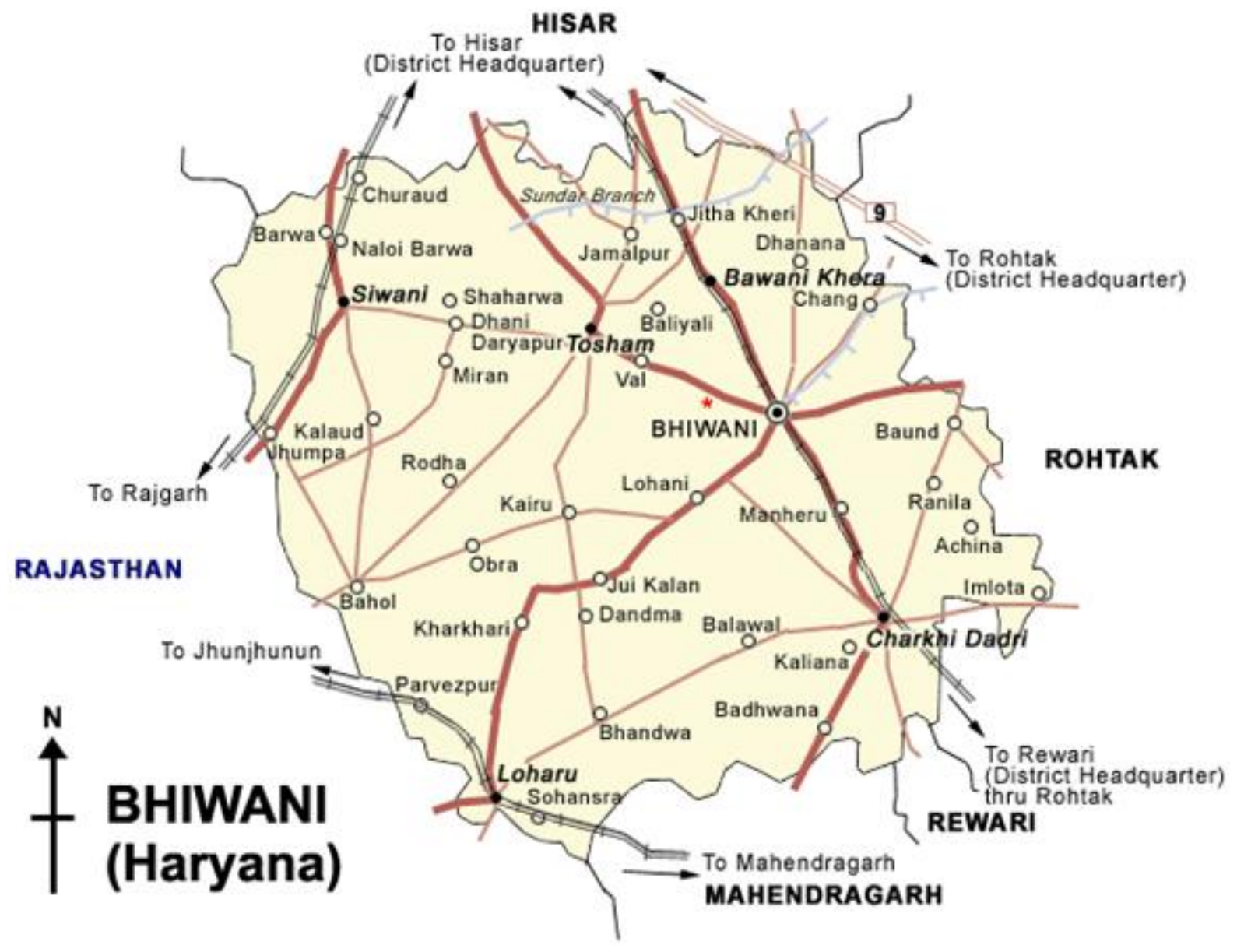

Fig.1: Main urban center ( Bhiwani city ) and its administrative areas: Dadri, Siwani, Loharu, Tosham and Bawanikhera administrative areas of Bhiwani district as per WHO/HAI Methodology. 


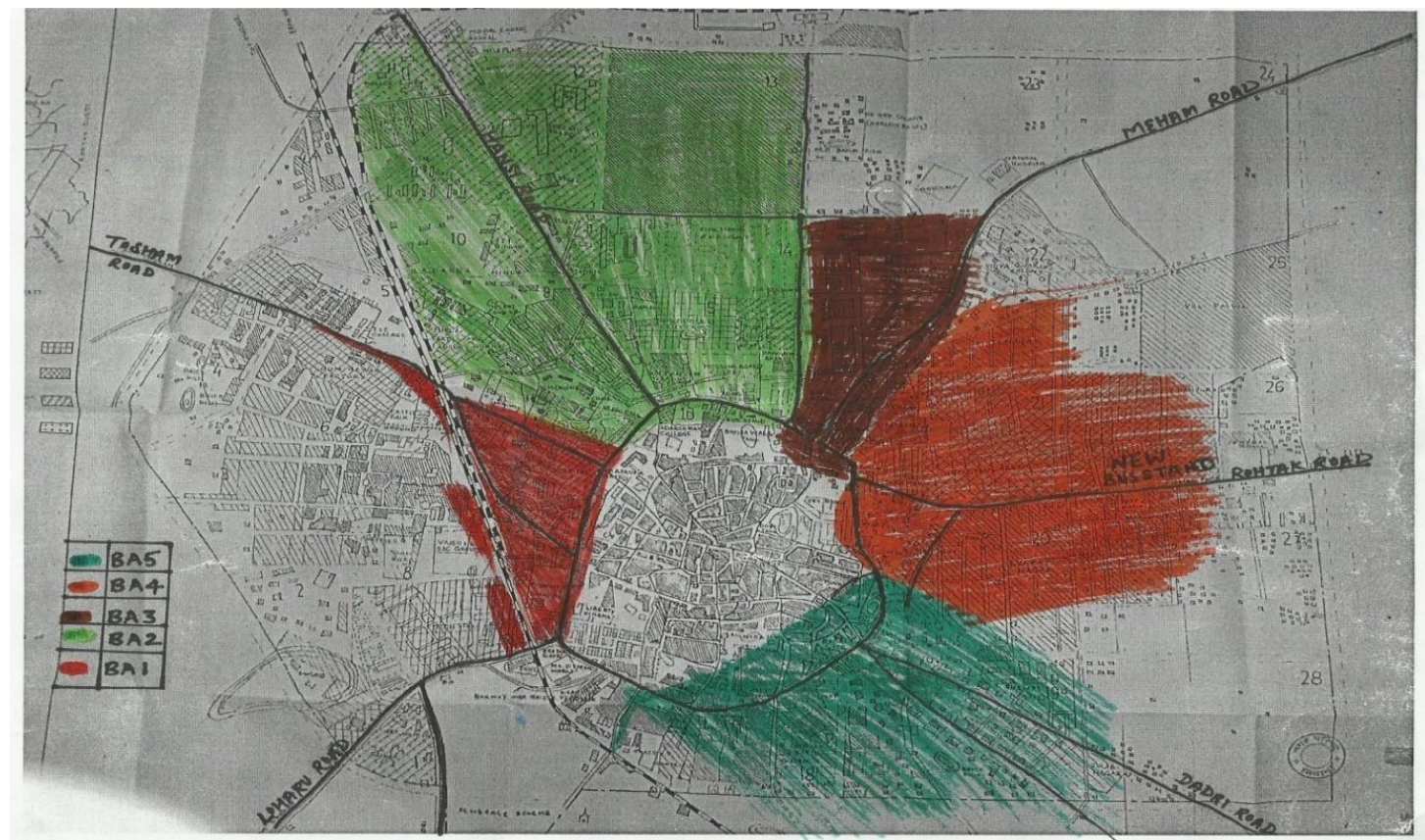

Fig. 2 Different Geographical areas of Bhiwani city: BA1 - Opposite Civil Hospital, Ghantaghar/ Bapura chowk, Krishna colony, Dinod Gate: BA2 - Hansi gate/ road, Opp. Old Bus stand, Sec -13, Friends colony, Chiriyaghar road, old housing board: BA3 - Meham Gate, Meham Road / Vidyanagar: BA4 - Rohtak gate/ road, M.C. Colony, New Bharat Nagar, Opp. New Bus Stand, Vikas Nagar: BA5 - Dadri Gate, Bawari Gate, Hanuman Gate

Table 1: List of selected essential medicines for selected chronic diseases.

\begin{tabular}{|c|c|c|c|}
\hline $\begin{array}{c}\text { Gastrointestinal- antiulcer } \\
\text { medicines }\end{array}$ & Anti-depressant medicines & Cardiovascular medicines & Anti diabetic medicines \\
\hline $\begin{array}{c}\text { Omeperazole } 20 \mathrm{mg} \text { cap/tab } \\
\text { Pantoprazole injection } 40 \\
\text { mg injection }\end{array}$ & $\begin{array}{l}\text { Amitriptyline } 25 \mathrm{mg} \text { cap/tab } \\
\text { Fluoxetine } 20 \mathrm{mg} \text { cap } / \mathrm{tab}\end{array}$ & $\begin{array}{l}\text { Amlodipine } 5 \mathrm{mg} \text { cap/tab } \\
\text { Atenolol } 50 \mathrm{mg} \text { cap/tab }\end{array}$ & $\begin{array}{c}\text { Glibenclamide } 5 \mathrm{mg} \text { cap/tab } \\
\text { Insulin injection (soluble) } 40 \mathrm{iu} / \mathrm{ml}\end{array}$ \\
\hline $\begin{array}{l}\text { Ranitidine } 150 \mathrm{mg} \text { cap/tab } \\
\text { Famotidine } 20 \mathrm{mg} \text { cap/tab }\end{array}$ & Imipramine $25 \mathrm{mg}$ cap/tab & $\begin{array}{c}\text { Enalapril } 5 \mathrm{mg} \text { cap } / \mathrm{tab} \\
\text { Losartan Potassium } 25 \mathrm{mg} \text { tab } \\
\text { Methyldopa } 250 \mathrm{mg} \mathrm{tab} \\
\text { Nifedipine } 20 \mathrm{mg} \text { cap } / \mathrm{tab} \\
\text { Sodium Nitroprusside inj. } 50 \mathrm{mg} / 5 \mathrm{ml} \\
\text { Hydrochlor thiazide } 25 \mathrm{mg} \mathrm{tab} / \mathrm{cap} \\
\end{array}$ & $\begin{array}{c}\text { Intermediate acting (lente/ NPH Insuline) } 40 \mathrm{iu} / \mathrm{ml} \\
\text { Premix Insulin 30:70 injection } 40 \mathrm{iu} / \mathrm{ml} \\
\text { Metformin 500mg cap/tab }\end{array}$ \\
\hline
\end{tabular}

\section{Methodology}

Percent availability of selected essential medicines used for the treatment of chronic diseases (Hypertension, Ulcer, Diabetes, Depression) in different geographical areas of Bhiwani city

In this procedure data was collected on the given format i.e. availability of selected essential medicines used for the treatment of chronic diseases in Bhiwani district. Percent availability of each surveyed medicine was calculated in each geographical area of Bhiwani city by dividing the number of retail pharmacy outlets having that medicine by total number of retail pharmacy outlets of that geographical area.

\section{Cumulative percent availability of selected essential medicines used for the treatment of selected chronic diseases in Bhiwani district}

In this procedure data was collected on the given format from Bhiwani city and five administrative areas (Dadri, Siwani, Loharu, Tosham, and Bawanikhera). Cumulative percent availability of each medicine was checked and it was divided by total number of retail pharmacy outlets of Bhiwani district.
Percent availability of each brand/generic of selected essential medicines used for the treatment of selected chronic diseases in different geographical areas (BA1, BA2, BA3, BA4, BA5) of Bhiwani city

In this procedure data was collected on the given format from Bhiwani city (BA1, BA2, BA3, BA4, BA5). The percent availability of each brand/generic in each geographical area was calculated by dividing the number of retail pharmacy outlets having that brand/generic by total number of retail pharmacy outlets in that geographical area.

\section{Percent availability of each brand/generic of selected essential medicines used for the treatment of selected chronic diseases in different geographical areas of Bhiwani city and five administrative areas of Bhiwani district}

In this procedure data was collected on the given format from Bhiwani city (BA1, BA2, BA3, BA4, BA5) and five administrative areas (Dadri, Siwani, Loharu, Tosham, Bawanikhera) of Bhiwani district. Percent availability of each brand/generic of each surveyed medicine for each geographical 
and administrative area was calculated separately and also for Bhiwani city.

\section{Cumulative Percent availability of total number of brands/generics of each selected medicine available in Bhiwani district}

In this procedure total number of brands/generics available for each surveyed medicine in Bhiwani district was collected on the given format in a specific administrative/ geographical area/main urban centre available in whole Bhiwani district.

\section{Data processing}

Percent availability of each selected medicine for selected chronic diseases in Bhiwani district and its administrative areas was analyzed by standard mean error.

\section{Ethical approval}

Ethical approval of the research study was obtained from Distt. Drug Controller Officer, Bhiwani and map of Bhiwani city was collected from municipal council, Bhiwani.

\section{RESULTS}

Overall percent availability of each surveyed medicine for selected chronic diseases in different geographical areas of Bhiwani district

Availability is presented as percentage of the essential medicines used for the treatment of chronic diseases (Hypertension, Ulcer, Diabetes, and Depression) found on retail pharmacy outlets surveyed. Overall percent availability of selected medicine for selected chronic diseases is $39 \%$ in Bhiwani district as shown in figure 3 .
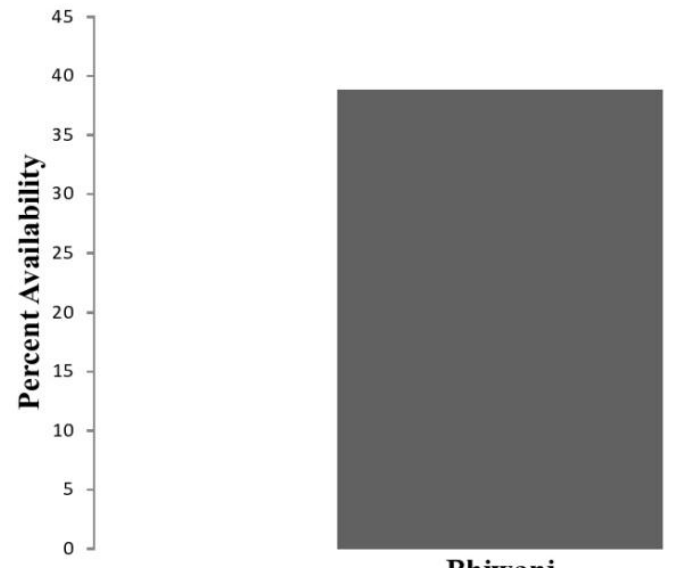

Bhiwani

Fig. 3: overall percent availability of selected medicine for selected chronic diseases in bhiwani district.

Percent availability of selected essential medicines for selected chronic diseases in Bhiwani district i.e. in Bhiwani city and its administrative areas is shown in the figure 4. Cumulative Percent availability of each surveyed medicine for selected chronic diseases in Bhiwani city i.e. in different geographical areas of Bhiwani is shown in figure 5 .

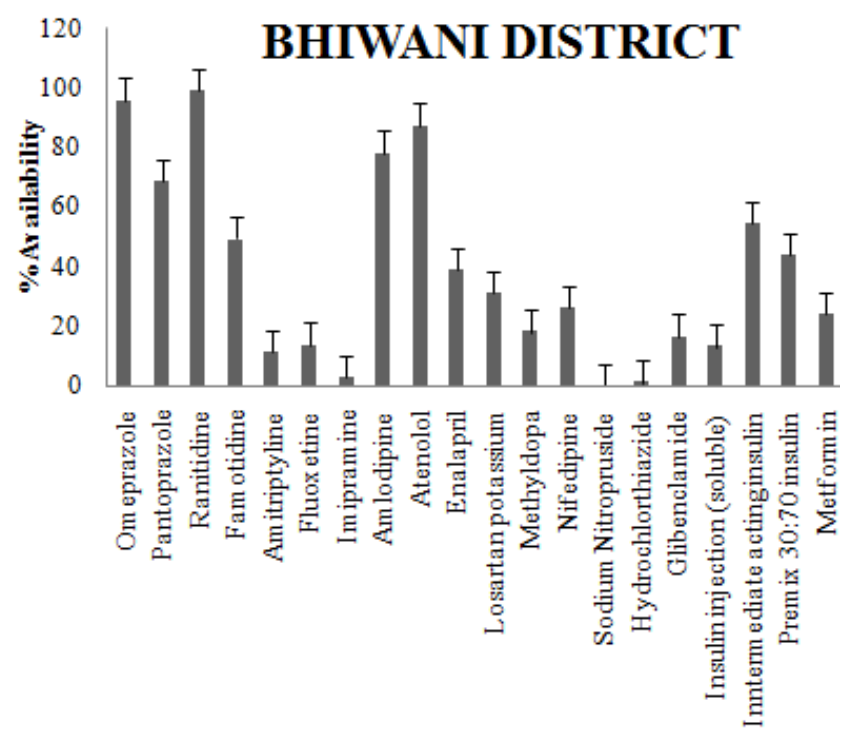

Fig. 4: Overall Percent availability of each surveyed medicine for selected chronic diseases in Bhiwani district.

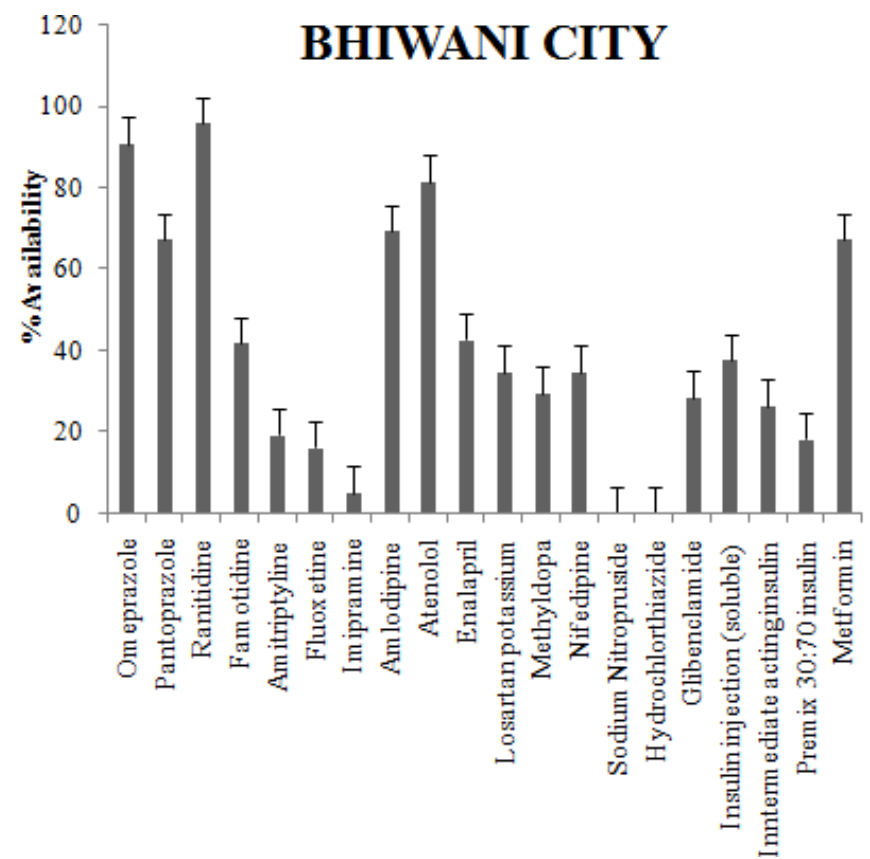

Fig. 5: Cumulative Percent availability of each surveyed medicine for selected chronic diseases in Bhiwani city.

Percent availability of surveyed medicine in Bhiwani district

Percent availability of each surveyed medicine for selected chronic diseases in Bhiwani city and its administrative areas is shown in the table 2.

Cumulative percent availability of surveyed medicine in Bhiwani district

Cumulative percent availability of each surveyed medicines for selected chronic diseases in Bhiwani district can be summarized as shown in the table 3 . 
Table 2: Percent availability of each selected medicine for selected chronic diseases in Bhiwani district and its administrative areas.

\begin{tabular}{|c|c|c|c|c|c|c|}
\hline Medicine & $\begin{array}{l}\text { Dadri } \\
\text { (\% availability } \\
\text { + S.E.M) }\end{array}$ & $\begin{array}{l}\text { Siwani } \\
\text { (\% availability } \\
\text { + S.E.M.) }\end{array}$ & $\begin{array}{l}\text { Loharu } \\
\text { (\% availability } \\
\text { + S.E.M) }\end{array}$ & $\begin{array}{l}\text { Tosham(\% availabil } \\
\text { ity+ S.E.M) }\end{array}$ & $\begin{array}{l}\text { Bawanikhera } \\
\text { (\% availabi-lity + } \\
\text { S.E.M) }\end{array}$ & $\begin{array}{l}\text { Bhiwani district } \\
\text { (\% availability } \\
\text { +S.E.M) }\end{array}$ \\
\hline Omeprazole & $100.0 \pm 7.08018$ & $100.0 \pm 8.525002$ & $91.66 \pm 7.281334$ & $93.33 \pm 7.70973$ & $100.0 \pm 8.380714$ & $95.9666 \pm 7.205807$ \\
\hline Pantoprazole & $86.66 \pm 7.08018$ & $81.81 \pm 8.525002$ & $33.33 \pm 7.281334$ & $53.33 \pm 7.70973$ & $88.88 \pm 8.380714$ & $68.5583 \pm 7.205807$ \\
\hline Ranitidine & $100.0 \pm 7.08018$ & $100.0 \pm 8.525002$ & $100.0 \pm 7.281334$ & $100.0 \pm 7.70973$ & $100.0 \pm 8.380714$ & $99.3183 \pm 7.205807$ \\
\hline Famotidine & $46.66 \pm 7.08018$ & $63.63 \pm 8.525002$ & $41.65 \pm 7.281334$ & $46.66 \pm 7.70973$ & $55.55 \pm 8.380714$ & $49.3283 \pm 7.205807$ \\
\hline Amitriptyline & $26.64 \pm 7.08018$ & $09.09 \pm 8.525002$ & $00.00 \pm 7.281334$ & $13.33 \pm 7.70973$ & $00.00 \pm 8.380714$ & $11.4066 \pm 7.205807$ \\
\hline Fluoxetine & $40.00 \pm 7.08018$ & $00.00 \pm 8.525002$ & $00.00 \pm 7.281334$ & $26.66 \pm 7.70973$ & $00.00 \pm 8.380714$ & $13.8300 \pm 7.205807$ \\
\hline Imipramine & $06.66 \pm 7.08018$ & $00.00 \pm 8.525002$ & $00.00 \pm 7.281334$ & $06.66 \pm 7.70973$ & $00.00 \pm 8.380714$ & $03.0700 \pm 7.205807$ \\
\hline Amlodipine & $89.91 \pm 7.08018$ & $72.72 \pm 8.525002$ & $66.54 \pm 7.281334$ & $93.33 \pm 7.70973$ & $77.77 \pm 8.380714$ & $78.2916 \pm 7.205807$ \\
\hline Atenolol & $93.33 \pm 7.08018$ & $81.81 \pm 8.525002$ & $74.97 \pm 7.281334$ & $93.33 \pm 7.70973$ & $100.0 \pm 8.380714$ & $87.5066 \pm 7.205807$ \\
\hline Enalapri & $46.62 \pm 7.08018$ & $45.45 \pm 8.525002$ & $33.33 \pm 7.281334$ & $33.33 \pm 7.70973$ & $33.33 \pm 8.380714$ & $39.1500 \pm 7.205807$ \\
\hline Losartan Pot. & $46.62 \pm 7.08018$ & $36.36 \pm 8.525002$ & $16.66 \pm 7.281334$ & $40.00 \pm 7.70973$ & $11.11 \pm 8.380714$ & $30.9050 \pm 7.205807$ \\
\hline Methyldopa & $43.29 \pm 7.08018$ & $18.18 \pm 8.525002$ & $00.00 \pm 7.281334$ & $06.66 \pm 7.70973$ & $11.11 \pm 8.380714$ & $18.1383 \pm 7.205807$ \\
\hline Nefidipine & $46.62 \pm 7.08018$ & $18.18 \pm 8.525002$ & $08.33 \pm 7.281334$ & $26.66 \pm 7.70973$ & $22.22 \pm 8.380714$ & $26.1150 \pm 7.205807$ \\
\hline Sod. Nitropruside & $00.00 \pm 7.08018$ & $00.00 \pm 8.525002$ & $00.00 \pm 7.281334$ & $00.00 \pm 7.70973$ & $00.00 \pm 8.380714$ & $00.0000 \pm 7.205807$ \\
\hline Hydrochlor-thiazide & $00.00 \pm 7.08018$ & $00.00 \pm 8.525002$ & $00.00 \pm 7.281334$ & $06.66 \pm 7.70973$ & $00.00 \pm 8.380714$ & $01.1100 \pm 7.205807$ \\
\hline Glibenclamide & $39.96 \pm 7.08018$ & $00.00 \pm 8.525002$ & $00.00 \pm 7.281334$ & $20.00 \pm 7.70973$ & $11.11 \pm 8.380714$ & $16.6050 \pm 7.205807$ \\
\hline Insulin inj. (Soluble) & $13.330 \pm 7.08018$ & $00.00 \pm 8.525002$ & $16.66 \pm 7.281334$ & $00.00 \pm 7.70973$ & $11.11 \pm 8.380714$ & $13.1400 \pm 7.205807$ \\
\hline $\begin{array}{l}\text { Intermediate acting } \\
\text { insulin inj }\end{array}$ & $60.00 \pm 7.08018$ & $90.90 \pm 8.525002$ & $33.33 \pm 7.281334$ & $73.33 \pm 7.70973$ & $44.44 \pm 8.380714$ & $54.7533 \pm 7.205807$ \\
\hline Premix insulin 30:70 inj. & $40.00 \pm 7.08018$ & $54.54 \pm 8.525002$ & $33.33 \pm 7.281334$ & $73.33 \pm 7.70973$ & $44.44 \pm 8.380714$ & $44.0000 \pm 7.205807$ \\
\hline Metformin & $46.62 \pm 7.08018$ & $09.09 \pm 8.525002$ & $00.00 \pm 7.281334$ & $33.33 \pm 7.70973$ & $22.22 \pm 8.380714$ & $24.2116 \pm 7.205807$ \\
\hline
\end{tabular}

Bhiwani district and its administrative areas: Dadri, Siwani, Loharu, Tosham and Bawanikhera.

Table 3: Percent availability of each surveyed medicine for selected chronic diseases in different geographical areas of Bhiwani city.

\begin{tabular}{|c|c|c|c|c|c|c|}
\hline Medicine & Bhiwani & BA1 & BA2 & $\overline{\text { BA3 }}$ & $\begin{array}{l}\mathbf{B A 4} \\
\end{array}$ & $\overline{\text { BA5 }}$ \\
\hline Omeprazole & 90.810 & 96.00 & 85.00 & 90.00 & 80.00 & 100.0 \\
\hline Pantoprazole & 67.340 & 76.00 & 50.00 & 75.00 & 60.00 & 72.22 \\
\hline Ranitidine & 95.910 & 92.00 & 95.00 & 100.0 & 93.33 & 100.0 \\
\hline Famotidine & 41.820 & 16.00 & 45.00 & 55.00 & 13.33 & 83.33 \\
\hline Amitriptyline & 19.380 & 04.00 & 25.00 & 30.00 & 20.00 & 22.22 \\
\hline Fluoxetine & 16.320 & 16.00 & 10.00 & 30.00 & 20.00 & 05.55 \\
\hline Imipramine & 05.100 & 00.00 & 00.00 & 25.00 & 00.00 & 00.00 \\
\hline Amlodipine & 69.380 & 80.00 & 65.00 & 70.00 & 33.33 & 88.88 \\
\hline Atenolol & 81.600 & 80.00 & 80.00 & 85.00 & 73.33 & 88.88 \\
\hline Enalapril & 42.840 & 48.00 & 20.00 & 40.00 & 40.00 & 66.66 \\
\hline Losartan Pot. & 34.680 & 48.00 & 15.00 & 45.00 & 20.00 & 38.88 \\
\hline Methyldopa & 29.590 & 32.00 & 20.00 & 50.00 & 26.66 & 16.66 \\
\hline Nefidipine & 34.680 & 36.00 & 25.00 & 45.00 & 13.33 & 50.00 \\
\hline Sod. nitropruside & 00.000 & 00.00 & 00.00 & 00.00 & 00.00 & 00.00 \\
\hline Hydrochlorthiazide & 00.000 & 00.00 & 00.00 & 00.00 & 00.00 & 00.00 \\
\hline Glibenclamide & 28.560 & 36.00 & 25.00 & 45.00 & 20.00 & 11.11 \\
\hline Insulin injection (Soluble) & 37.740 & 68.00 & 15.00 & 55.00 & 13.33 & 22.22 \\
\hline $\begin{array}{l}\text { Intermediate acting (lente/NPH) } \\
\text { insulin injection }\end{array}$ & 26.520 & 44.00 & 25.00 & 35.00 & 00.00 & 16.66 \\
\hline Premix insulin 30:70 injection & 18.360 & 16.00 & 00.00 & 45.00 & 06.66 & 22.22 \\
\hline Metformin & 67.340 & 40.00 & 65.00 & 75.00 & 40.00 & 72.22 \\
\hline
\end{tabular}

Bhiwani city and its different geographical areas

BA1 - Opposite Civil Hospital, Ghantaghar/ Bapura chowk, Krishna colony, Dinod Gate. BA2 - Hansi gate/ road, Opp. Old Bus stand, Sec -13, Friends colony, Chiriyaghar road, old housing board. BA3 - Meham Gate, Meham Road / Vidyanagar. BA4 - Rohtak gate/ road, M.C. Colony, New Bharat Nagar, Opp. New Bus Stand, Vikas Nagar. BA5 - Dadri Gate, Bawari Gate, Hanuman Gate. 
Table 4: Cumulative percent availability location/area of each surveyed medicine for selected chronic diseases in Bhiwani District.

\begin{tabular}{|c|c|c|}
\hline Cumulative \% Availability in (\%) & Name of medicine (with cumulative \% availability) & Availability location/area \\
\hline \multirow{3}{*}{$00-05$} & Sodium Nitroprusside inj. (0\%) & N.A. \\
\hline & Hydrochlorthiazide (1.11\%) & Tosham \\
\hline & Imipramine $(3.07 \%)$ & Dadri, Tosham, BA3 \\
\hline $05-10$ & N.A. & \\
\hline \multirow[t]{3}{*}{$10-15$} & Amitriptyline ( $11.40 \%)$ & Dadri, Siwani, Tosham, Bhiwani \\
\hline & Insulin Injection (soluble) (13.14\%) & Dadri,Loharu,Bhiwani, bawanikhera \\
\hline & Fluoxetine $(13.83 \%)$ & Dadri, Tosham, Bhiwani \\
\hline \multirow{2}{*}{$15-20$} & Glibenclamide (16.60\%) & All over except Loharu, Siwani \\
\hline & Methyldopa (18.13\%) & All over except Loharu \\
\hline $20-25$ & Metformin $(24.21 \%)$ & All over except Loharu \\
\hline $25-30$ & Nifedipine $(26.11 \%)$ & All \\
\hline $30-35$ & Losartan Potassium $(30.90 \%)$ & All \\
\hline $35-40$ & Enalapril $(39.15 \%)$ & All \\
\hline $40-45$ & Premix Insulin 30:70 (44\%) & All over except BA2 \\
\hline $45-50$ & Famotidine $(49.32 \%)$ & All \\
\hline $50-55$ & Intermediate acting (lente/ NPH Insuline) $(54.75 \%)$ & All over except BA4 \\
\hline $55-60$ & N.A. & \\
\hline $60-65$ & N.A. & \\
\hline $65-70$ & Pantoprazole (68.55\%) & All \\
\hline $70-75$ & N.A. & \\
\hline $75-80$ & Amlodipine $(78.29 \%)$ & All \\
\hline $80-85$ & N.A. & \\
\hline $85-90$ & Atenolol $(87.50 \%)$ & All \\
\hline $90-95$ & N.A. & \\
\hline \multirow[t]{2}{*}{$95-100$} & Omeprazole (95.96\%) & All \\
\hline & Ranitidine $(99.31 \%$ ) & All \\
\hline
\end{tabular}

Table 5: List of Brands/Generics available for each surveyed medicine in Bhiwani district.

\begin{tabular}{ll}
\hline Name Of Medicine & Brands/Generics available for each medicine in Bhiwani district \\
\hline Omeprazole & Ocid, Omitome, Omez-insta, Ometac, Nogacid, Omesec, Omecip, Pikloz, Lomak, Omecid, Ometab, O.D. \\
Pantoprazole & P-PPI, Pantin, Pantocid, Panta G, Pantodex, Pan i.v., Pantodac, Panto- i.v., Pentab, Pantowok, Panver, Pantosec, Makoos, \\
& Pantocip, Nicopenta, Pentome \\
Ranitidine & Rantac, Zinetac, Aceloc, Histak, Monorin, Zantac, Ranitidine, Peloc \\
Famotidine & Famocid, Famonext, Topcid, Famotec \\
Amitriptyline & Tryptomer, Amitome, Elavil, Sarotena \\
Fluoxetine & Fludac, Prodep, Flunil, Fluty \\
Imipramine & Dapsonil, Tencodep \\
Amlodipine & Amlovas, Amlopress, Amodep, Amlokind, Amlodac, Amtas, Aginal \\
Atenolol & Aten-50, Atecard, Cardules, Tenoric, Tenolol, Hipres, Hipress \\
Enalapril & Envas, Dilvas \\
Losartan Potassium & Losar, Losakind, Loram- H, Omnitan \\
Methyldopa & Alphadopa \\
Nifedipine & Nicardia, Depin, Nefidine \\
Sod. Nitroprusside inj. & Not available \\
Hydrochlorthiazide & Altem \\
Glibenclamide & Daonil, Glinil, Glibet, Glynase \\
Insulin inj. (soluble) & Human Actrapid, Lupisulin, Wosulin, Huminsulin- R, Insugen, Lantus, Lupinsulin-M-30, Human insulin \\
Intermediate acting insulin inj. & Human mixtard, Lupinsulin- N, Huminsulin- N, Human insulin \\
Premix insulin 30:70 inj. & Huminsulin 30/70, Lupisulin 30/70, Insugen 30/70 \\
Metformin & Glycomet, Metatime, Walaphage, Glyciphage, Gluformin, Carbophage, Gluconorm, Exermet, Sugarmet \\
\hline
\end{tabular}

\section{Availability of surveyed medicines and its brands}

According to World Health Organization and Health Action International (WHO \& HAI) manual 2008; each medicine has originator brand i.e. international originator brand product for the medicine and generic equivalent is all products other than originator brand that contain same active ingredient whether marketed under a brand name or the generic name. Availability of number of brands of selected essential medicines for selected common ailments is shown in table 5 .

\section{Availability of most selling and low priced sold brand of selected essential medicines}

Most selling or available brands/generics found for the surveyed medicines for chronic diseases in Bhiwani city were
Ocid, P-PPI, Rantac, Faocid, Tryptomer, Fludac, Dapsonil, Amodep, Aten, Atecard, Envas, Losar, Alphadopa, Daonil, Nicardia, Actrapid, Mixtard, Huminsulin 30/70 and Glycomet.

Lowest priced brands/generics found for the surveyed medicines in bhiwani city were Omesec, Pentab, Monorin, Famonext, Amitome, Prodep, Dapsonil, Amodep, Hipres, Envas, Losakind, Alphadopa, Depin, Glibet, Actrapid, Human mixtard, Walaphage, Glyciphage.

\section{DISCUSSION}

Bhiwani covers a larger geographical area as compare to other districts of Haryana state. Therefore, in order to get more précised results about the percent availability each surveyed 
medicine, it is necessary to cover maximum geographical area. This research study should be useful to government health policy makers in providing a broad picture of the present situation regarding availability of selected essential medicines used for the treatment of the chronic diseases. Dissemination of well documented information on availability to medicine consumers in all residential areas may enhance consumer demand for lower price medicine and thus may serve to enhance the availability of demanded medicine in all the areas of Bhiwani district. The present study is perhaps the only study that compares the availability of selected essential medicine for selected chronic diseases in a single district of any state.

This research study covers those retail pharmacy outlets of Bhiwani district who gave response and showed interest in this practice and serve to document the overall availability, availability of most selling brands/generics, low priced sold brands/generics, availability of number of brands of selected essential medicines used for the treatment of chronic diseases in different geographical areas and shall be source of information; which medicine is available in which area of Bhiwani district. From this study, People of Bhiwani will come to know about the availability of each medicine in their area which is usually not known. This data would serve as reference for consumers, policy makers or nongovernmental organizations interested to take up such projects.

\section{Overall availability}

The availability of most of medicines was found to be good except Imipramine, Sodium nitropruside and hydrochlorothiazide (Less than $5 \%$ availability). For many medicines, only one version of the product was available that was the costly or branded medicine (popular name) or the availability of cheaper options was very low. Therefore, the consumer has no option to buy that costly branded product. Retail pharmacy outlets stock those medicines that are mostly prescribed by doctors; indicates that doctors tend to prescribe branded medicines to consumers. People are suffering as they do not know exactly what is the difference between cheaper brands/generics and expensive brands/generics they prefer only the prescribed brands/generics. The availability of brands/generics was found to be maximum for Pantoprazole (total no. of brands/generics- 16) and Omeprazole (total no. of brands/generics- 12) in bhiwani district.

\section{Policy options to improve availability}

Awareness about the medicine brands/generics options in community could be beneficial to people in selecting a cheaper medicine and therefore availability of that product may enhance in market as the consumer would demand for that option at retail pharmacy outlets. Lower availability of few medicines is due to inefficient purchasing or distribution in the retail pharmacy outlets (Cameron et al., 2009; Kotwani, 2011). For improving availability of essential medicines various recommendations such as Government to increase the budget of medicines, prepare Standard treatment guidelines (STGs) and EML on the basis of essential medicine concept; separate EML for primary care and hospitals; procurement and distribution of medicines on the basis of EML; prescription according to STGs and EML and regular monitoring and evaluating system (Quick, 2003; Holloway, 2011).

\section{CONCLUSION}

From observations in the present study, overall percent availability of the maximum of the surveyed medicines was found to be less than $50 \%$. Also, for the available medicines there is a difference in the most selling and cheapest brands/generics i.e. most selling brands/generics are not always the cheapest available brands/generics. As the patients suffering from chronic diseases have to use the medicines for a longer period of time and also the expenditure is more, they should make aware about cheaper options. The availability of cheaper options in market can be increased if the consumers always demand for the cheaper options.

\section{REFERENCES}

Barcelo A, Aedo C, Rajpathak S and Robles S. The cost of diabetes in Latin America and the Caribbean. Bulletin of the World Health Organization , 2003; 81(1).

Cameron A, Ewen M, Ross-Degnan D, Ball D and Laing R. Medicine prices, availability, and affordability in 36 developing and middle-income countries. A secondary analysis, The Lancet, 2009; 373:240-249.

Cameron A, Roubos I, Ewen M, Mantel-Teeuwisse A, Leufkens $\mathrm{H}$, and Laing R. 2011. Differences in the availability of medicines for chronic and acute conditions in the public and private sectors of developing countries.

Ewen M. Sound price data-sound price policies. Essential drug monitor, 2003; 33:23.

FDA center for drug evaluation and research, Office of generic drugs. What are generic drugs? The US Food and Drug Administration (FDA), 2009. Available at: http://www.fda.gov/Drugs/ ResourcesForYou/Consumers/BuyingUsingMedicineSafely/ Understanding Generic Drugs/ucm144456.html

Godman B, Shrank W, Andersen M, Berg C, Bishop I, Burkhardt T, Garuoliene K, Herholz H, Joppi R, Kalaba M, Laius O, Mcginn D, Samaluk V, Sermet C, Schwabe U, Teixeira I, Tilson L, Tulunay FC, Vlahovic-Palcevski V, Wendykowska K, Wettermark B, Zara $\mathrm{C}$, and Gustafsson LL. Comparing policies to enhance prescribing efficiency in Europe through increasing generic utilization: changes seen and global implications. Expert Rev. Pharmacoecon. Outcomes Res, 2010; 10:707-722.

Holloway K. Combating inappropriate use of medicines. Expert Rev Clin Pharmacol. 2011; 4:335-348.

Kotwani A. 2011. Report on: Medicine prices, availability, affordability, and medicine price components in NCT, Delhi, WHO/HAI methodology.

NEML. 2011. National list of essential medicines of India, Directorate General of Health Services, Ministry of Health and Family Welfare. Government of India, New Delhi.

Quick JD, Hogerzeil HV, Velasquez G, and Rag L. Twenty-five years of essential medicines. Bulletin of the World Health Organization, 2002; 80:913-914.

Quick JD. Ensuring access to essential medicines in the developing countries: a framework for action. Clin Pharmacol Ther. 2003; 73:279-83.

Shafie AA and Hassali MA. Price comparison between innovator and generic medicines sold by community pharmacies in the state of Penang. Malaysia. J Generic Med, 2008; 6:35-42.

Sheppard A. Generic medicines. Essential contributors to the long-term health of society, 2011. Available:http://www.imshealth.com/ 
imshealth/Global/Content/Document/Market_Measurement_TL/Generic_ Medicines_GA.pdf.

World Health Organization \& Health Action International. 2003.. Measuring medicine prices, availability, affordability and price components. $1^{\text {st }}$ edition, Geneva, Switzerland.

World Health Organization. 2005. Preventing chronic diseases. A vital investment: WHO global report, Geneva, Switzerland.

World Health Organization \& Health Action International. 2008. Measuring medicine prices, availability, affordability and price components. $2^{\text {nd }}$ edition, Geneva, Switzerland.

World Health Organization. 2008. WHO Chronic Diseases Report. World Health Organization, Geneva: Switzerland.
World Health Organization. 2011. The world medicines situation 2011, Access to essential medicines as part of the right to health. World Health Organization, Geneva, Switzerland.

\section{How to cite this article:}

Shashikant Jangra, Neeraj Gilhotra., Comparative Availability of Selected Essential Medicines for Selected Chronic Diseases in Bhiwani District, Haryana, India. J App Pharm Sci, 2015; 5 (09): 131-138. 